\title{
Reestruturação nos Bancos no Brasil: Desemprego, subcontratação e intensificação do trabalho
}

\author{
Liliana Rolfsen Petrilli Segnini *
}

\begin{abstract}
RESUMO: Este trabalho procurou comprender as mudanças e as implicações no mercado de trabalho, na organização e no conteúdo do trabalho observadas no processo de reestruturação produtiva no setor bancário, em São Paulo. Para tanto enfocou as especificidades da racionalização do trabalho bancário, com o objetivo de analisar as qualificações requeridas e observadas em diferentes formas de relações empregatícias, em tal reestruturação. Esta análise considerou as relações de gênero nos processos produtivos apontados, por compreendê-las relevantes e necessárias para este estudo. O desemprego, a terceirização do trabalho como forma de precarização social, a intensificação do trabalho e a relativização das exigências de uma "nova qualificação" do bancário foram os principais resultados discutidos neste artigo.
\end{abstract}

Palavras-chave: Trabalho, qualificação, relação de gênero, reestruturação, bancários.

Este trabalho procurou comprender as mudanças e implicações no mercado de trabalho, na organização e no conteúdo do trabalho observadas no processo de reestruturação produtiva no setor bancário, em São Paulo, maior centro financeiro do Brasil e da América Latina. ${ }^{1}$

\footnotetext{
Departamento de Ciências Sociais Aplicadas à Educação, Faculdade de Educação, Universidade Estadual de Campinas.
} 
Para tanto enfocou as especificidades da racionalização de diferentes processos de trabalho que constituem o trabalho bancário, com o objetivo de analisar as qualificações requeridas e observadas (escolaridade, qualificação técnica e social, competências), em diferentes formas de relações empregatícias, no processo de reestruturação produtiva em curso no setor. Esta análise considerou as relações de gênero nos processos produtivos apontados, por compreendê-las relevantes e necessárias para apreender mais amplamente o objeto deste estudo.

Nesse sentido, considerando que os diferentes processos de trabaIho estudados são portadores de especificidades próprias, foram analisados os locais de trabalho que, em uma pesquisa prévia, informaram ser relevantes para a realização da atividade bancária. Assim, foram enfocadas diferentes formas de atendimento ao cliente (agências bancárias, centrais de atendimento e os chamados bancos virtuais); o suporte tecnológico nos bancos (departamento de processamento de dados); o suporte ao registro de documentos e valores (o centro de compensação de cheques); o suporte à qualificação do trabalhador bancário (departamento de treinamento $e$ formação profissional).

Os processos de trabalho acima referidos foram analisados considerando a heterogeneidade das formas de inserção no trabalho - trabalho em tempo integral, trabalho em tempo parcial, trabalho terceirizado -, bem como as relações de gênero observadas, conforme já salientado. Para tanto, foi realizada uma análise comparativa entre um banco estatal, um banco privado nacional e um banco privado estrangeiro, pois, de acordo com suas trajetórias históricas, acrescentam singularidades à análise, possibilitando uma compreensão mais ampla do que venha a ser o trabalho bancário no Brasil.

O referido processo de reestruturação dos bancos é compreendido como uma das características constitutivas do processo de reestruturação do próprio capitalismo, mais amplo e complexo do que ocorre no âmbito dos espaços produtivos; trata-se de um processo de intensificação da internacionalização do capital, acompanhado pela expansão do ideário neoliberal.

Especificidades do processo de reestruturação no sistema bancário: Fusões, incorporações e privatização

O processo de reestruturação do capitalismo se expressa no sistema financeiro adequando-o a um novo patamar de acumulação, ca- 
racterizado pela importância da esfera financeira no comando da repartição e destinação social da riqueza. A reorganização do sistema financeiro global e o emergente poder da coordenação financeira caracterizam-se pela proliferação e pela descentralização das atividades financeiras, criação de novos instrumentos e mercados.

As mudanças no mercado financeiro intensificam a velocidade de circulação dos capitais, subjugam o capital produtivo à redução das taxas de crescimento, submetem os Estados-Nação à livre circulação de recursos e aumentam a instabilidade macroeconômica nos mercados nacional e internacional (Mattoso 1992). Dessa forma, a desregulamentação do sistema e as inovações (novos produtos e serviços) no setor vieram a ser consideradas condição de sobrevivência para qualquer centro financeiro mundial inserir-se no sistema global integrado por um sistema telemático instantâneo.

Essa dinâmica insere-se num contexto de intensificação da mundialização dos mercados e dos fluxos financeiros, cuja velocidade possibilita a concretização da internacionalização dos bancos, ampliando a interpenetração dos diversos mercados nacionais.

Nesse sentido, o sistema financeiro assume um duplo papel: ao mesmo tempo em que atua como agente no processo de reestruturação mais amplo, também vivencia reestruturações nos processos produtivos no sentido de se adequar à lógica de "livre mercado" que norteia a intensa competição já outrora existente, porém intensificada nesse setor.

\section{Especificidades da reestruturação no Brasil}

No Brasil, assim como em outros países, em um aparente paradoxo, o Estado atua fortemente por meio de políticas econômicas e financeiras, adequando o sistema financeiro do país às características mencionadas, consideradas por organismos internacionais - como, por exemplo, o Banco Mundial - como necessárias para um processo de "ajuste" das economias nacionais às exigências de uma nova ordem mundial caracterizada, politicamente, por propostas neoliberais. "O desenvolvimento baseado no mercado pode reduzir as desigualdades e a pobreza nos países em desenvolvimento", afirma o Banco Mundial (1995), ao prescrever um conjunto de ações políticas e econômicas para os Estados nacionais, no contexto "da integração mundial". 
A estabilização da moeda em 1994, pelo Plano Real, foi um marco nesse sentido, após tentativas frustradas de vários planos econômicos com esse mesmo objetivo, iniciadas em 1986 com o Plano Cruzado. O processo de reestruturação do sistema financeiro no Brasil, sob a coordenação do Banco Central e de acordo com esta instituição regulatória e fiscalizadora, resulta em três modalidades de "ajustes" do sistema bancário. ${ }^{2}$

Em primeiro lugar, destacam-se as medidas relativas ao número de empresas, ou seja, falências, fusões e incorporações, privatizações. Os ajustes relativos à redução do número de empresas são considerados, pelo Banco Central, de dois tipos: não-voluntários e voluntários.

Os "ajustes não-voluntários" referem-se a 40 bancos que sofreram intervenção por parte do Banco Central, a partir da estabilização da moeda pelo Plano Real, em 1994. As principais intervenções ocorreram nos bancos Econômico, Bamerindus e Nacional. Esses ajustes envolveram os citados grandes bancos, e também bancos médios e pequenos, considerados "vulneráveis" e cuja situação "explodiu" após o Plano Real, posto que tanto a lucratividade que auferiam como os dados que ocultavam em balanços financeiros, tornaram-nos inviáveis econômica e financeiramente.

O problema da "crise de confiança" no sistema financeiro, no caso dos grandes bancos, e a justificativa da "estabilidade sistêmica" foram apontados como elementos que justificaram a ação do Banco Central, implementando o Proer - Programa de Estímulo à Reestruturação e ao Fortalecimento do Sistema Financeiro Nacional, em 3/11/95. Tal programa foi apresentado como propiciador de estabilidade financeira, sobretudo no que tange os grandes bancos privados nacionais, livrando o sistema de "risco sistêmico", cabendo ao Banco Central do Brasil absorver a "parte ruim" dos bancos (dívidas), sobretudo dos grandes bancos acima citados. Os processos de intervenção nos bancos estatais, também efetivados pelo Banco Central do Brasil, preparou-os, nesse mesmo sentido, para a privatização "da parte boa" dos bancos.

Os "ajustes voluntários" ocorreram sobretudo no segmento de bancos médios, envolvendo aquisições, fusões e incorporações a partir de iniciativas dos próprios bancos, procurando melhores condições de competitividade no mercado, possibilitando intenso processo de concentração bancária no país. Ganhos de escala, ampliação de redes de agências e de carteira de clientes, aproveitamento de tecnologias e espaços compartilhados são fatores relevantes nesse processo. 
Dessa forma, a rede bancária no Brasil, em 1993, era constituída por 245 bancos, 17.194 agências e 13.326 postos de atendimento; em maio de 1997, 225 bancos significavam 16.418 agências e 14.859 postos de atendimento. $O$ processo de concentração bancária, por meio de corporações, fusões e privatizações, possibilitou a expansão da participação do capital estrangeiro no sistema bancário, sobretudo no setor de varejo bancário, pela intermediação financeira e política do Banco Central do Brasil.

Todas essas medidas provocaram uma forte redução no mercado de trabalho bancário, tanto pela eliminação de postos de trabalho superpostos, superposição de agências, reestruturação das formas de gestão, fusão de postos de trabalho, bem como pelo uso intensivo das tecnologias da informação. Dessa forma, se em 1986 a categoria representava um milhão de trabalhadores, em 1996 foi reduzida para 497 mil bancários, ou seja, em dez anos, 503 mil postos de trabalho foram suprimidos.

Em segundo lugar, o Banco Central aponta para os "ajustes" relativos à composição dos produtos bancários, os quais se referem às estratégias do setor objetivando a manutenção e a ampliação das carteiras de clientes e de lucratividade, num contexto de intensa concorrência entre os bancos. Assim, é observada uma oferta crescente de produtos e serviços, sendo que a receita de serviços tende a crescer em detrimento da receita de créditos ao consumidor. Não obstante, esta ainda prevalece sobre a primeira, de acordo com a instituição citada.

Finalmente, em terceiro lugar, são salientados os "ajustes" referentes ao "aparato regulatório" do sistema bancário, envolvendo mudanças no sistema de garantia de créditos. Isso quer dizer que, para a abertura de um banco, a partir de 1996, passou a ser exigido $32 \%$ dos ativos, sendo que para os já existentes $8 \%$ era considerado suficiente. Além dessa alteração, houve aumento do poder de intervenção do Banco Central na administração dos bancos.

No contexto acima descrito, caracterizado por permanente lucratividade, mesmo que as altas taxas registradas no período inflacionário fossem reduzidas no período de estabilização da moeda, é observada uma drástica redução no emprego bancário, atribuída a diversos fatores que caracterizam a reestruturação produtiva do setor, refletida no mercado de trabalho. 


\section{Rentabilidade dos bancos}

\begin{tabular}{|l|l|l|l|l|l|l|l|l|l|l|l|}
\hline 1985 & 1986 & $\mathbf{1 9 8 7}$ & $\mathbf{1 9 8 8}$ & $\mathbf{1 9 8 9}$ & $\mathbf{1 9 9 0}$ & $\mathbf{1 9 9 1}$ & $\mathbf{1 9 9 2}$ & $\mathbf{1 9 9 3}$ & $\mathbf{1 9 9 4}$ & $\mathbf{1 9 9 5}$ & $\mathbf{1 9 9 6}$ \\
\hline 17,9 & 13,4 & 19,8 & 11,7 & 15,8 & 12,6 & 7,0 & 8,9 & 12,3 & 12,7 & 7,98 & 13,81 \\
\hline
\end{tabular}

Fonte: Austin Asis/Sisbacem. In: Dados Gerais do Sistema Bancário. Febraban, junho de 1997

Além dos programas de "ajuste" acima apontados, como fusões e incorporações, privatização de bancos estatais, é possível apontar um conjunto de medidas que objetiva a minimização dos custos, e que afeta diretamente o emprego bancário. A partir do momento que a inflação deixou de ser uma fonte segura de lucratividade para os bancos, essas tendências, observadas desde a década de 1970, intensificaram-se:

1) a evolução bem como o uso intensivo das tecnologias de informação, informática e telemática permitiram automatizar serviços para reduzir custos e aumentar a segurança e a qualidade dos serviços disponibilizados para uma parcela da população, via fax, telefones, computadores em escritórios e residências;

2) a terceirização de um volume crescente de trabalhos considerados "não bancários" como transporte, segurança, limpeza, engenharia e manutenção de prédios e equipamentos, restaurante, desenvolvimento de softwares. Posteriormente, serviços bancários também passaram a ser terceirizados como análise de crédito, compensação de cheques e as centrais de atendimento;

3) diferentes formas de gestão que objetivam a fusão de postos de trabalho, a redução dos níveis hierárquicos como Programas de Reengenharia. Mesmo os Programas de Qualidade, implantados como programas de melhoria das condições de trabalho, adotaram sobretudo medidas propostas pelos Círculos de Qualidade que possibilitaram a redução de custos e a maximização de resultados financeiros. Salários não foram jamais discutidos nesses círculos, como bem informam os depoimentos nesta pesquisa.

Esse processo, tanto no plano macroeconômico e social - referente à adequação do sistema financeiro nacional a um mercado mundializado, expressão da reestruturação do próprio capitalismo - como no plano micro, da organização do trabalho, implicou mudanças observadas no emprego e na escolaridade dos bancários, como será analisado a seguir. 


\section{O trabalho bancário no contexto da reestruturação: Desemprego, precarização e intensificação do trabalho}

As mudanças referentes à organização do trabalho no interior dos bancos são compreendidas como sendo expressão desse processo mais amplo acima descrito, de opções econômicas, políticas e sociais, e não simplesmente decorrentes de aspectos tecnológicos.

Nesse sentido, os bancos analisados, aparentemente, implementam práticas de gestão diferenciadas, relações salariais também diferenciadas, em decorrência tanto de suas próprias histórias como dos segmentos de mercado em que atuam. Também vivenciam graus diferenciados de difusão tecnológica. No entanto, as diferenças observadas entre eles ocorrem muito mais em termos quantitativos do que efetivamente qualitativos, quer dizer, são implementadas estratégias que apontam para a mesma direção: racionalização do trabalho pela minimização de custos e pela ampliação de serviços competitivos num mercado também cada vez mais competitivo. Assim, nestas considerações finais, pretende-se apontar para o que foi possível apreender do conjunto de instituições e processos de trabalho analisados.

Três fenômenos sociais caracterizam o processo de reestruturação nos bancos e estão completamente imbricados com a questão central desta pesquisa, ou seja, "a nova qualificação do bancário". São eles:

1) Intenso desemprego - Em 1986, a categoria bancária no Brasil representava um milhão de trabalhadores; em 1996, 497 mil, conforme dito anteriormente. A elevada taxa de desemprego no setor referese a diferentes políticas que objetivam a redução de custos, num contexto altamente competitivo. Assim, é possível destacar a eliminação e a fusão de postos de trabalho, em decorrência das práticas de gestão que possibilitam a flexibilização funcional do trabalho (que se traduz pela realização de várias tarefas ao mesmo tempo), a redução de níveis hierárquicos e a opção política e econômica que embasa o uso das inovações tecnológicas, determinando, ao mesmo tempo, crescimento da produtividade e a redução de postos de trabalho, sem contudo alterar a jornada de trabalho dos que permanecem empregados. Pelo contrário, é registrado um número maior de horas extras, de acordo com as entrevistas realizadas. 


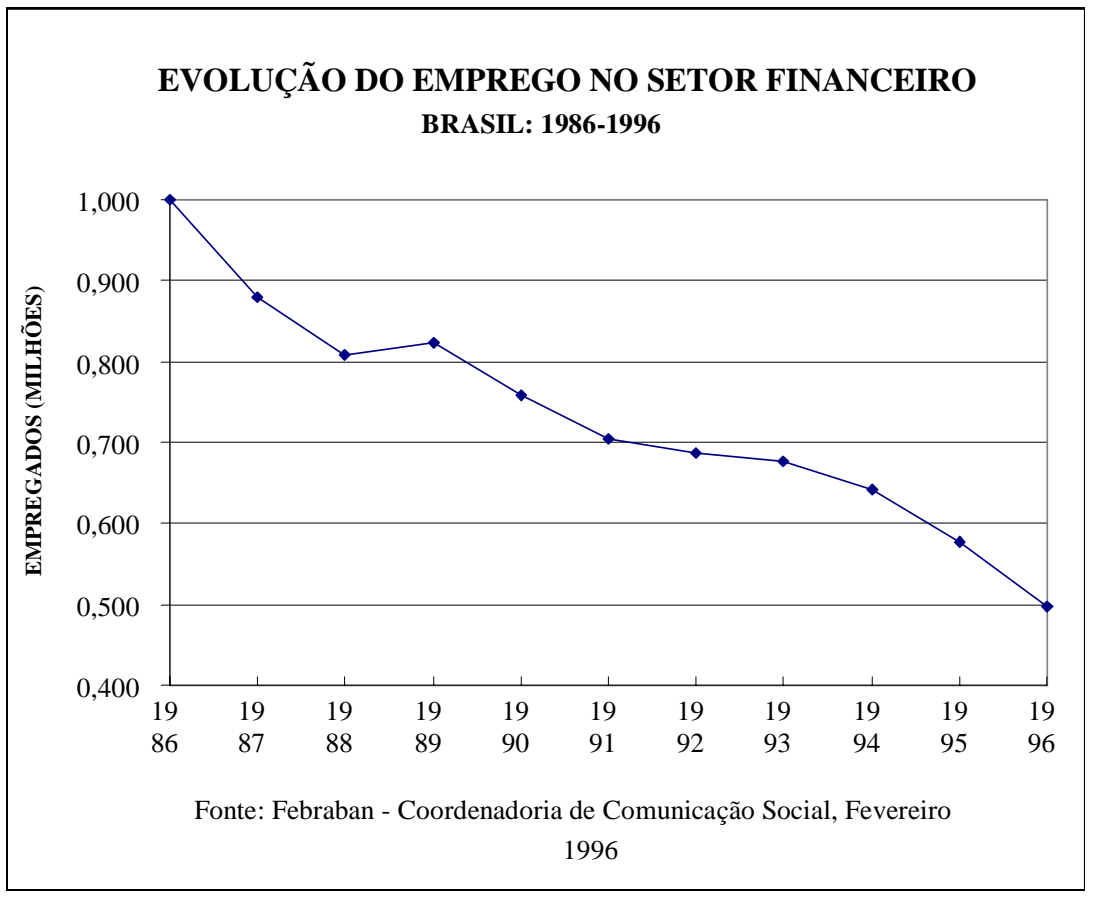

Os postos de trabalho passíveis de um grau elevado de normatização - como, por exemplo, caixa de banco, encarregado da separação de documentos e cheques, digitador - foram os mais atingidos pela racionalização através do desenvolvimento de softwares que possibilitaram a transferência de tais tarefas para o cliente, no momento da realização da operação bancária (auto-atendimento), ou para o funcionário que as executa. Dessa forma, é observada uma redução mais intensa do trabalho em tempo parcial, executado por bancários denominados escriturários. Essas tarefas, na sua grande maioria, não implicam um alto grau de qualificação porque são repetitivas, comumente submetidas a tempos predefinidos. No entanto, exigem um alto grau de atenção e responsabilidade, características que os bancos consideram, com freqüência, femininas.

As mulheres, majoritariamente, são escriturárias, o que possibilita levantar a hipótese de que elas estejam vivenciando o desemprego mais intensamente do que os homens, após 35 anos de crescimento da 
participação feminina nesse setor da economia. Não há dados quantitativos confiáveis que confirmem essa colocação no que se refere aos bancos privados enfocados.

O banco estatal vivencia também um processo de redução de postos de trabalho, em decorrência de mudanças nas formas de gestão e difusão tecnológica mas, sobretudo, por estar sob intervenção do Banco Central do Brasil, num processo que o prepara para a privatização, em conformidade com os programas de "ajuste" já citados. Com esse objetivo foram criados os Programas de Demissão Voluntária e Estímulo à Aposentadoria; no início de 1997 foi criado um Programa de Demissão Dirigida. Assim, em 1988, o número de funcionários no banco estatal era 38 mil (41\% mulheres); em 1993, entre 35.339 trabalhadores, $47 \%$ eram mulheres; em 1997 seu quadro de funcionários foi reduzido para 23 mil, sendo que, entre eles, as mulheres passaram a representar $49 \%$. Durante o período 1993/97, 121 agências consideradas não-rentáveis foram fechadas.

O desemprego atingiu homens e mulheres no banco estatal, porém mais intensamente os escriturários (não comissionados), que trabaIhavam nas agências. Os homens, tanto em números absolutos como relativos, aderiram aos Programas de Demissão mais intensamente do que as mulheres.

\begin{tabular}{|c|c|c|c|c|c|c|r|}
\hline Período & \multicolumn{6}{|c|}{ Programa de Demissão Voluntária - Banco do Estado } \\
\hline & Depart. & Agen. & comission/ & $\begin{array}{c}\text { não } \\
\text { comission/ }\end{array}$ & homens & mulheres & total \\
\hline jun/ 95 & 140 & 759 & 219 & 680 & 530 & $369(41 \%)$ & 899 \\
\hline $\mathrm{dez} / 95$ & 192 & 1.074 & 384 & 882 & 736 & $530(41 \%)$ & 1.266 \\
\hline $\mathrm{jul} / 96$ & 58 & 464 & 84 & 438 & 305 & $217(41 \%)$ & 522 \\
\hline $\mathrm{ag} / 97$ & 286 & 1.937 & - & - & 1246 & $977(43 \%)$ & 2.223 \\
\hline
\end{tabular}

Fonte: Departamento de Recursos Humanos - Banco de Dados - Banco Estatal, 1997

Nos Programas de Estímulo à Aposentadoria, o número de comissionados cresce, assim como o de trabalhadore(a)s nos departamentos. No entanto, novamente os números absolutos revelam um maior número de homens, não comissionados, trabalhando em agências. 


\begin{tabular}{|c|c|c|c|c|c|c|r|}
\hline Período & \multicolumn{6}{|c|}{ Programa de Estímulo à Aposentadoria - Banco do Estado } \\
\hline & Depart. & Agen. & comission/. & $\begin{array}{c}\text { não } \\
\text { comission/ }\end{array}$ & homens & mulheres & total \\
\hline 1996 & 325 & 1.051 & 627 & 749 & 707 & $669(48 \%)$ & 1.376 \\
\hline $\mathrm{ag} / 97$ & 176 & 793 & - & - & 539 & $430(44 \%)$ & 969 \\
\hline
\end{tabular}

Fonte: Departamento de Recursos Humanos - Banco de Dados - Banco Estatal, 1997

Observa-se, assim, que houve uma redução de $35 \%$ dos funcionários do banco, sendo $40 \%$ homens e $30 \%$ mulheres.

Nesse sentido, dois aspectos precisam ser destacados. Em primeiro lugar, as mulheres passaram a ter direito a se inscrever em concurso público nos bancos estatais, no Brasil, somente após o final da década de 1960 e o crescimento do número de mulheres no setor foi gradativo; portanto, há um número menor de mulheres com direito a aderir ao Programa de Incentivo à Aposentadoria. Em segundo lugar, a análise das entrevistas realizadas informa sobre o processo de precarização das condições de trabalho no banco do Estado, outrora um espaço privilegiado em termos de condições de trabalho e relações salariais.

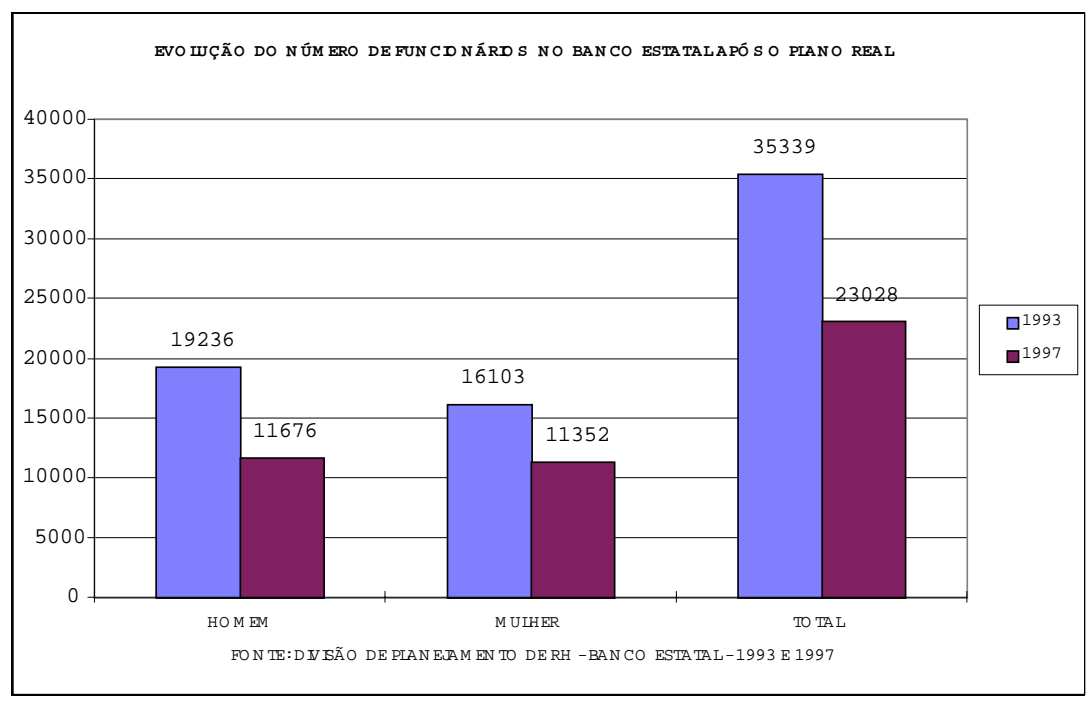




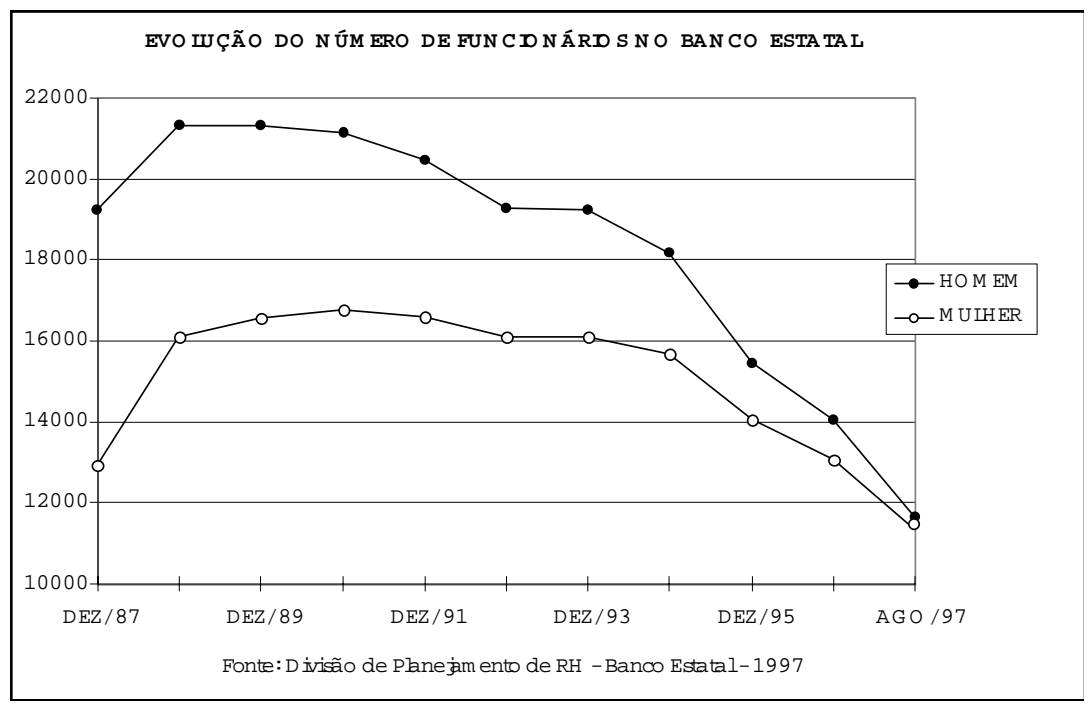

No entanto, o crescimento relativo da participação feminina nesse banco não altera, ou melhor, pouco altera a estrutura de poder nas relações de gênero observada em trabalho anterior (Segnini 1998), mesmo considerando que os homens aderiram em número maior aos programas propostos para redução de quadros. As mulheres continuam predominantemente no trabalho em tempo parcial (84\%), hierarquicamente inseridas em trabalhos de suporte às tarefas administrativas e comerciais; porém, mais e mais solicitadas para realizar trabalho de vendas, assim como os bancários de forma geral.

O desemprego de trabalhadores em decorrência do processo de reestruturação acrescenta uma nova dimensão aos problemas sociais que já marcam há muito o Brasil - até então, miséria, pobreza, falta de acesso à educação e à saúde. Trata-se do desemprego de trabalhadores escolarizados e qualificados, como é o caso dos bancários. Essa problemática social, ainda não estudada no Brasil, coloca indagações para pesquisas no âmbito da sociologia do trabalho e da sociologia da educação.

2) Terceirização e precarização do trabalho - Nos processos terceirizados em questão (compensação de cheques, telemarketing, desenvolvimento de softwares, serviços de courrier) foi possível regis- 
trar, comparando-os com os mesmos processos realizados nos bancos, redução de custos e índices de produtividade mais elevados obtidos pelo uso das mesmas tecnologias implementadas tanto pelas empresas terceirizadoras como pelos bancos. Intensificação do trabaIho, jornadas de trabalho mais longas, freqüentes horas extras, salários relativamente inferiores informam as práticas de gestão que determinam a precarização do trabalho em relação à mesma tarefa efetuada nos bancos. Somando-se às condições de trabalho, a permanente incerteza em relação à permanência no trabalho contribui na construção da precarização social. ${ }^{3}$

Por outro lado, o desemprego elevado no setor possibilita que bancários anteriormente qualificados pelos bancos sejam contratados pelas terceirizadoras de serviços em condições precárias, sobretudo em relação aos direitos trabalhistas. Na empresa terceirizadora de compensação de cheques, dos quatro mil funcionários, 95\% haviam trabalhado em banco anteriormente. O salário de um compensador nessa empresa representa $33 \%$ do salário no banco estatal na mesma função, e $70 \%$ no banco privado estrangeiro. A jornada de trabalho é freqüentemente desrespeitada e mais longa em comparação aos bancos.

Dessa forma, a "flexibilidade numérica", ou seja, a possibilidade de admitir e demitir de acordo com as demandas do mercado e dos processos de trabalho, se reafirma como importante estratégia de minimização de custos nos bancos estudados. Uma análise de gênero a respeito dos processos de terceirização observados revela que as empresas terceirizadoras reafirmam os estereótipos referentes aos atributos masculinos e femininos na construção das qualificações desejadas na execução das tarefas.

No serviço de compensação de cheques, espaço predominantemente masculino de trabalho, tanto na empresa terceirizadora como nos bancos, o reduzido número de mulheres é justificado pelo horário noturno, que o torna "perigoso para as mulheres na hora de sair do trabalho"; ou ainda, simplesmente, que "esse não é um ambiente adequado para mulheres porque o trabalho aqui é tenso, muita correria, e os rapazes ficam à vontade". No entanto, é sempre reafirmado que "nunca mulher foi discriminada aqui".

Afirmações como essas, que atribuem fragilidade à "natureza" feminina, não Ihes possibilitando acesso a esse tipo de tarefa, são recriadas na tarefa de operadora nas centrais de atendimento, marcando, 
ao contrário do serviço de compensação de cheques, o teleatendimento como sendo predominantemente feminino. As mulheres são consideradas mais apropriadas para a tarefa em decorrência de atributos pessoais, construídos com base em estereótipos sexistas, como: "voz mais suave", "convincente", "são mais disponíveis para ouvir", "mais pacienciosas". Além disso, em decorrência do número de crimes praticados por mulheres ser, estatisticamente, inferior ao dos homens, a voz feminina é considerada "mais confiável" para realizar operações bancárias a distância.

Dessa maneira, no contexto da reestruturação dos bancos, a qualificação feminina permanece extremamente vinculada aos atributos pessoais, desejados mas não reconhecidos em termos salariais pelos bancos. O trabalho em telemarketing tem sido realizado sobretudo por jovens mulheres brancas, com terceiro grau incompleto, estudantes estagiários, com boa dicção e bom domínio da língua portuguesa. Os salários são equivalentes ao salário de escriturário, portanto encontram-se nos níveis inferiores da categoria bancária (entre $\mathrm{R} \$ 500,00$ e $\mathrm{R} \$ 700,00$ ). Nas empresas terceirizadoras o salário é em torno de $25 \%$ a $30 \%$ menor.

3) Intensificação do trabalho - Quanto aos bancários que permanecem empregados, nos diferentes processos de trabalho enfocados, foi possível observar a intensificação do trabalho tanto pela fusão de postos de trabalho, pela diminuição dos níveis hierárquicos, como pelas exigências decorrentes de programas de gestão como, por exemplo, os Programas de Reengenharia, que buscam a minimização dos custos, ou Programas de Qualidade, que procuram a maximização dos resultados.

Nesse sentido, o medo da perda do emprego, sempre presente em todas as entrevistas e nos debates em grupo, constitui-se em grande motivador para o trabalho, em tempos de discursos participacionistas. As entrevistas realizadas nos diversos locais de trabalho - nas agências, tanto no trabalho de suporte do atendimento ao cliente, como no trabaIho diretamente vinculado ao cliente, no processamento de dados, na compensação de cheques, no teleatendimento - registram que o bancário compreende estar trabalhando mais intensamente, comumente realizando horas extras, percebendo salários relativamente menores em comparação com os anos anteriores. No entanto, revela compreender também que dessa forma mantém o emprego, transformando o medo em produtividade. Por intermédio da "pedagogia do medo" do desemprego, o bancário qualifica-se, de acordo com o conceito atribuído a essa expressão pelos bancos. 
O desemprego, nas entrevistas, aparece como expressão da atual conjuntura marcada por forte competição interbancária, estabilização da moeda e difusão da informática. Porém, a representação do desemprego já vivido pelo colega reafirma o medo do próprio desemprego, atribuindo-Ihe culpabilidade por não ter sabido "captar o momento", "produzir de acordo com o que o banco pedia" ou tantas outras formas de exprimir a "improdutividade" do outro, daquele que se desemprega.

Os salários são também constituídos de modo a reafirmar esse processo de valorização do individualismo, somado ao medo do desemprego na construção de índices de produtividade elevados. Isso quer dizer que os salários são cada vez mais "flexíveis", constituídos de restrita parcela fixa e vários itens variáveis, que possibilitam a auferição diária, mensal, do "valor" do funcionário em relação aos parâmetros preestabelecidos, com sua própria anuência.

Considerando as características gerais acima apontadas, observadas no trabalho bancário no contexto da reestruturação, compreendese a "nova qualificação" do bancário.

\section{O fetiche da qualificação mais elevada dos bancários}

Quanto à questão central desta pesquisa - a nova qualificação do bancário no contexto da reestruturação dos bancos - observam-se paradoxos e contradições fortemente relacionados ao contexto de desemprego intenso, precarização e intensificação do trabalho, bem como o crescimento da competição e da produtividade observadas no setor.

Considerar esses aspectos, inicialmente, em uma análise que privilegia os contornos das "novas qualificações" permite apreender melhor o seu significado, ou seja, o que vem a se constituir qualificação para o trabalho nesse contexto.

A categoria bancária distingue-se, há muito tempo, de outras categorias profissionais no Brasil, por ser altamente escolarizada. Os bancos selecionam seus funcionários no mínimo com primeiro grau completo ( 8 anos de estudo), com forte predominância do segundo grau (11 anos de estudo) e terceiro grau (16 anos de estudo) desde a década de 1960, a partir da reforma bancária. O que se observa, em termos comparativos com a atual conjuntura, é que, efetivamente, cresce o número de bancá- 
rios com terceiro grau e decresce a porcentagem de bancários com apenas primeiro e segundo graus. Essa constatação tem possibilitado tanto aos bancos como aos sindicatos dos bancários afirmar que, no contexto da reestruturação dos bancos, é requerido um novo e mais elevado patamar de qualificação dos bancários.

\begin{tabular}{|r|r|c|l|l|l|l|}
\hline \multicolumn{7}{|c|}{ DISTRIBUIC̃O DOS BANCÁRIOS POR GRAU DE INSTRUC̃OO-SÃO PAULO 1989-93 } \\
\hline Anos & Total & $1^{\circ}$ grau & $\begin{array}{l}2^{\circ} \text { grau } \\
\text { Incompleto }\end{array}$ & $\begin{array}{l}2^{\circ} \text { grau } \\
\text { Completo }\end{array}$ & $\begin{array}{l}3^{\circ} \text { grau } \\
\text { Incompleto }\end{array}$ & 3o grau Completo \\
\hline 1989 & 100,0 & 22,3 & 15,9 & 31,7 & 11,4 & 18,7 \\
\hline 1990 & 100,0 & 20,6 & 14,1 & 33,7 & 13,1 & 18,6 \\
\hline 1991 & 100,0 & 19,4 & 12,4 & 32,9 & 14,9 & 20,4 \\
\hline 1992 & 100,0 & 16,0 & 11,2 & 35,5 & 12,7 & 24,6 \\
\hline 1993 & 100,0 & 14,6 & 9,8 & 34,4 & 15,6 & 25,6 \\
\hline
\end{tabular}

Fonte: SPG. Convênio Seade - Dieese, 1994

Nesta pesquisa, a análise dos postos de trabalho não confirma a colocação acima como decorrência do conteúdo destes mesmos postos e processos de trabalho. O que se observa é que os procedimentos para executálos tendem a ser cada vez mais simplificados e seguros, com a difusão das tecnologias de informação e submetidos a controles mais rígidos, tanto para os postos de trabalho passíveis de alto grau de normatização (escriturário, caixa, compensador), como para aqueles que vivenciam forte tensão entre os procedimentos pré-normatizados, padronizados, e a particularidade, ou seja, aqueles que estabelecem relação direta com o cliente. Por exemplo: na função de gerente, a particularidade de cada caso, a singularidade que cada cliente representa é minimizada pela construção de softwares que, pelo preenchimento de ficha cadastral, informa o "valor" (em termos de riscos e rentabilidade) desse cliente. Assim, no limite de sua alçada, o gerente pode autorizar ou não a transação financeira. Para as operações de valores mais elevados, comitês de crédito (grupo de gerentes ou diretores) aprovam a operação, como já faziam anteriormente. Outros tantos exemplos foram registrados ao longo deste relatório. Nesse sentido, torna-se necessário saber utilizar esses programas, de comandos simples, que não demandam longo processo de formação; ao contrário, comumente é o próprio colega que, no dia-a-dia, informa como proceder.

Nesta pesquisa entende-se que os índices de escolaridade mais elevados registrados nos bancos referem-se não a uma exigência do 
conteúdo próprio ao posto de trabalho, mas a um longo processo de desemprego que possibilita privilegiar, para permanecer empregado, os bancários mais escolarizados, entre os outros que vão sendo excluídos desse segmento do mercado de trabalho.

\section{Qualificação descrita: A valorização de competências} bancos?

Qual seria, então, o significado da "nova qualificação" na ótica dos

Em termos gerais, num contexto de intensa concorrência interbancária e de redução de custos, conforme já apontado em diferentes momentos neste texto, qualificação, na perspectiva dos bancos, expressa a capacidade de competir, com sucesso, tanto com colegas de trabaIho na execução de serviços internos, na busca de um desempenho diferencial cada vez melhor, como no mercado financeiro, vendendo produtos e serviços bancários. Isso quer dizer que, na ótica dos bancos, ser capaz e ter disposição para competir, ser capaz de ser "um vencedor" marca e caracteriza competências, compreendidas como sendo qualificação (Ropé e Tanguy 1997).

Essa afirmação depreende-se tanto das entrevistas realizadas como das descrições e observações dos postos de trabalho. Assim, é apontado como qualificação para ocupá-los: "ser capaz de se adaptar à intensificação do ritmo de trabalho e às demandas dos clientes", "disposição para ser competitivo", "ser amável", "equilibrado", "ser capaz de se adaptar às novas situações", "ter comportamento social adequado" etc.

Portanto, um conjunto de processos sociais, econômicos e culturais é mobilizado na construção da socialização "para o mercado"; além, sem dúvida, da grande importância adquirida pelos atributos pessoais. Observa-se também que a importância do diploma, em termos de conteúdo (qualidade), é relativizada, adquirindo muito mais um caráter legitimador do posto de trabalho ocupado do que mobilizador de conhecimentos.

Vários exemplos foram destacados neste relatório; salienta-se, para citar alguns, gerência, caixa de banco, teleatendimento, compensador e até mesmo analista de sistemas, ou seja, para os postos de trabalho que implementam políticas já previamente definidas pela alta direção dos ban- 
cos. Para as funções que projetam políticas e procedimentos a serem cumpridos por toda a instituição (alta direção), registra-se a exigência de diplomas obtidos nas melhores escolas do país, freqüentemente com pósgraduação no exterior; mas tal exigência não se constitui em característica singular do processo de reestruturação produtiva.

A análise baseada na divisão social por gênero confirma a relativização da importância do diploma, em termos de conhecimentos exigidos nos bancos, reafirmando a qualificação como expressão de relações sociais. Nesse sentido, considera-se a qualificação para o trabaIho como relação social (de classe, de gênero, de etnia, geracional), que se estabelece nos processos produtivos, no interior de uma sociedade regida pelo valor de troca e fortemente marcada por valores culturais. Isso quer dizer que os conhecimentos adquiridos pelo trabalhador em diferentes processos e instituições sociais - família, escola, empresa etc. -, somados às suas habilidades, também adquiridas socialmente, acrescidas de suas características pessoais, de sua subjetividade, constituem um conjunto de saberes e habilidades que significa, para ele, trabalhador, valor de uso. Este só se transforma em valor de troca nos processos produtivos, num determinado momento histórico, se reconhecido pelo capital como sendo relevante para o processo produtivo.

O reconhecimento do grau de qualificação do trabalhador pelas organizações produtivas se dá por sua particular inserção em diferentes níveis hierárquicos e salariais, em diferentes formas de relações empregatícias como trabalho em tempo integral, tempo parcial ou subcontratado (Segnini 1998).

Assim, os aspectos sociais que constroem "a nova qualificação", que efetivamente valorizam as competências individuais do bancário, reafirmam o que já foi dito por Ropé e Tanguy (1997, p. 206) a propósito do contexto francês, ou seja, que as organizações estão realizando "(...) uma busca obstinada por individualização". Como corolário dessa questão, é percebido que o fosso entre aqueles que vivenciaram trajetórias sociais que Ihes possibilitaram a aquisição das competências valorizadas em um contexto competitivo e aqueles que só se escolarizaram se aprofunda.

As mulheres, conforme registrado aqui, são mais escolarizadas do que os homens, mas ocupam cargos hierarquicamente inferiores. No entanto, mesmo nos cargos mais elevados - gerente pessoa física - as competências e os atributos femininos são descritos sobretudo com base na construção dos estereótipos que marcam a desigual divisão sexual do 
trabalho: as mulheres "têm mais paciência e jeitinho para cuidar de muitas contas de pequeno valor do que os homens"; "se dedicam mais", "são mais atenciosas".

No banco estatal, ao contrário dos bancos privados, é observada uma redução em todos os níveis hierárquicos do grau de escolaridade no banco. Assim, cresce o número de funcionários com superior incompleto e decresce o número dos que já o concluíram, possibilitando dois tipos de questionamento a respeito da propagada importância de níveis de escolaridade mais elevados em um contexto de reestruturação produtiva.

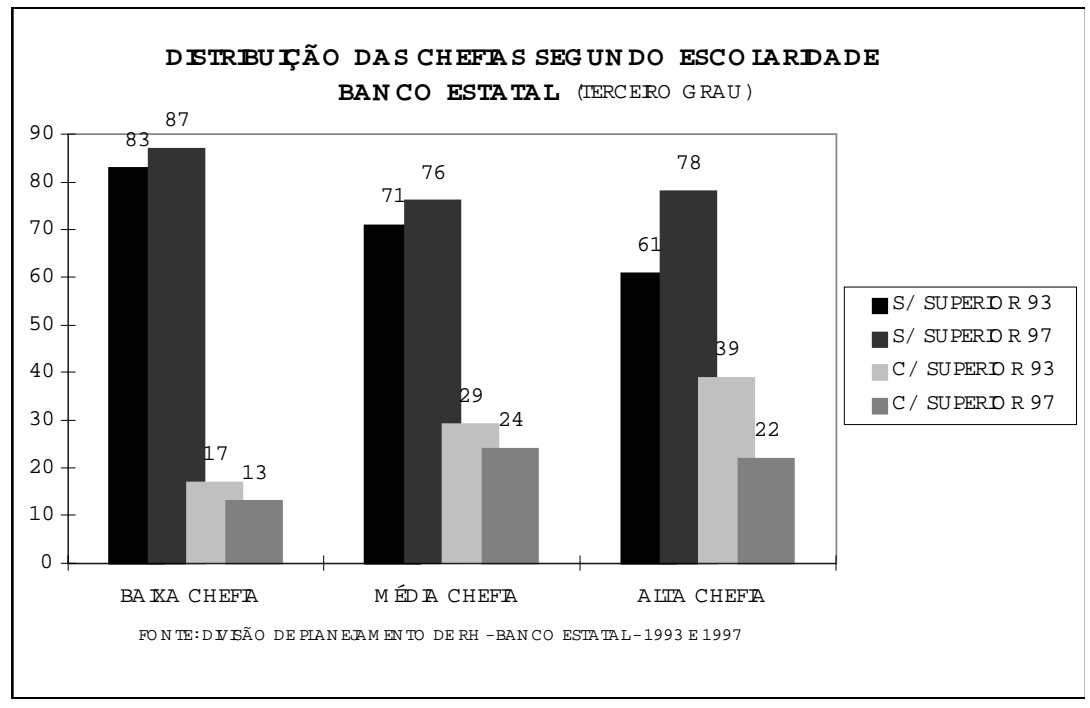

Da mesma forma, um olhar sobre a questão dos gêneros também possibilita relativizar a perspectiva que procura relacionar reestruturação produtiva e níveis mais elevados de escolaridade. Assim, se em 1993 as mulheres representavam 55\% dos bancários com terceiro grau, em 1996 elas passaram a representar $61 \%$. Tal defasagem se acentua no trabalho não comissionado (escriturários) que, conforme já salientado, implica tarefas que demandam menos tempo de treinamento, mas muita atenção e responsabilidade. Os salários são significativamente menores. 


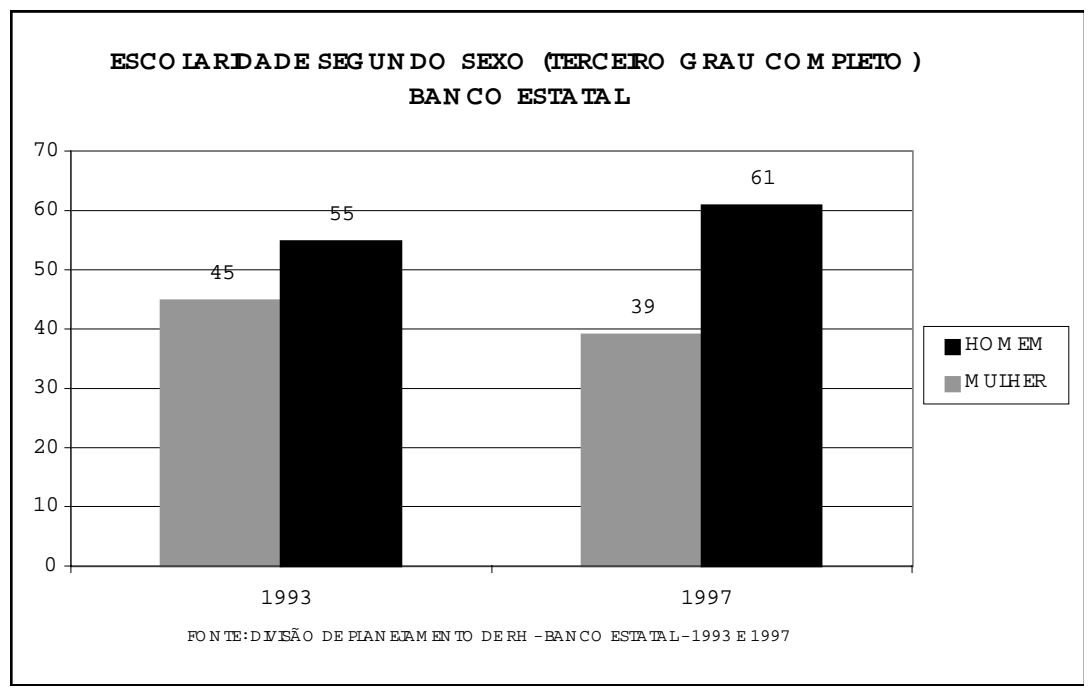

Esses dados permitem novamente indagar quanto é relativo o diploma para ocupar a grande maioria dos postos de trabalho nos bancos; por outro lado, questionar a possível desestruturação de instituições estatais em processo de privatização, com base nas características que as distinguiram até então: elevado grau de escolaridade e qualificação de seus funcionários, que eram acompanhados por índices salariais mais elevados e direitos sociais conquistados. Nesse contexto, ao contrário dos bancos privados, cresce a participação das mulheres no banco estatal.

\section{Considerações finais}

O trabalho bancário durante décadas representou, para muitos jovens, uma estratégia de continuidade nos estudos de terceiro grau, por significar uma jornada de trabalho de 6 horas diárias para, posteriormente, deixarem o banco e seguir sua própria profissão. $O$ trabalho bancário era compreendido, pelos jovens bancários ingressantes, como "provisório". Posteriormente, por representar meIhores condições de trabalho e carreira em comparação com outros 
setores profissionais, foi, pouco a pouco, adquirindo um caráter "definitivo", como bem analisou Romanelli (1978). Desta análise decorre que, sociologicamente, a carreira bancária possibilitava o desenvolvimento de um processo de escolarização e carreira.

Hoje, os bancários são mais velhos, mais escolarizados, como revelam os dados estatísticos. Porém, a intensa pressão por produtividade e a competição entre os próprios colegas marcam a precariedade do vínculo com a instituição, a possibilidade real de desemprego a qualquer momento. Dessa forma, no contexto da reestruturação produtiva, o emprego nos bancos deixa de ser caracterizado como provisório, que se transforma em definitivo, para se constituir em definitivamente provisório.

\section{Notas}

1. Este texto resgata as considerações finais do projeto de pesquisa intitulado "Novas formas de relações empregatícias e qualificações requeridas em um contexto altamente informatizado: Análise do sistema financeiro no Brasil", realizado pela equipe composta por Liliana Rolfsen Petrilli Segnini (coord.), Fernando Antônio Pinheiro Filho (auxiliar científico), Andrea Ranieri Luciano, Selma Borghi Venco e Simone Mussnich Rotta (auxiliares de pesquisa). Durante períodos determinados também participaram da equipe os professores Leila Maria Gonçalves Hernandez, Josué Pereira da Silva (subcoordenadores) e Helena Bins Ely (auxiliar científico). Vincula-se ao projeto integrado que enfoca diferentes subsetores da economia, intitulado "Produção e Qualificação", convênio Cedes/Finep/ PCDT-CNPq, período 1995/1997. Agradecemos a professoradoutora Zeila de Brito F. Demartini por suas valiosas orientações metodológicas.

2. Moura 1997. As palavras entre aspas expressam vocábulos específicos do jargão do Banco Central do Brasil.

3. Castel 1998, pp. 514 e 516: "Mas o desemprego é apenas a manifestação mais visível de uma transformação profunda da conjuntura do emprego. A precarização do trabalho constitui-Ihe uma outra característica, menos espetacular porém mais importante, sem dúvida. (...) Não para banalizar a gravidade do desemprego. Contudo, enfatizar essa precarização do trabalho permite compreender os processos que alimentam a vulnerabilidade social e produzem, no final do percurso, o desemprego e a desfiliação." 


\section{A Restructure in Brazilian Banks: unemployment, sub-hiring and work intensification.}

ABSTRACT: This survey sought to understand the changes and work market implications, in the organization and in the work content observed in the process of productive restructure in the banking sector, in São Paulo. For such matter, it pointed out the specificity of the rationalizing of different work processes that form the banking work, required and observed qualifications, in different forms of hiring relations, in the process of productive restructure underway in the sector. This analysis considered the gender relations in the productive processes focussed, understanding them being relevant and necessary to perceive in a wider way the objective of this survey. The unemployment, the outsourced services as a form of social precariousness, the intensification of work and the relative way of the demand of a "new qualification" about the bank clerk were the main results discussed in this article.

\section{Bibliografia}

ANTUNES, Ricardo. Adeus ao trabalho? Ensaio sobre as metamorfoses e a centralidade do mundo do trabalho. $2^{\underline{a}}$ ed. São Paulo: Cortez; Campinas: Editora da Unicamp, 1995.

APPAY, Béatrice e THÉBAUD-MONY, Annie. Précarisation sociale, travail et santé. Paris: Iresco, 1997.

AUBERT, Nicole e GAULEJAC, Vincent. Le coût de l'excellence. Paris: Seuil, 1991.

BALTAR, Paulo Eduardo de A., DEDECCA, Cláudio S. e HENRIQUE, Wilnês. "Mercado de trabalho e exclusão social no Brasil". Campinas: Cesit/Unicamp, s.d. (Mimeo.)

BANCO MUNDIAL. RELATÓRIO SOBRE O DESENVOLVIMENTO MUNDIAL. O trabalhador e o processo de integração mundial. Washington, 1995.

BERMAN, Marshall. Tudo que é sólido desmancha no ar. A aventura da modernidade. São Paulo: Companhia das Letras, 1986.

BERNIER, Colette. La polyvalence des emplois. Montreal: Institut de Recherche Apliquée sur le Travail - IRAT. nº 22, out. 1982. 
BOYER, Robert. La flexibilité du travail en Europe. Paris: La Découverte, 1986.

BRAVERMAN, Harry. Trabalho e capital monopolista. A degradação do trabalho no século XX. Rio de Janeiro: Zahar Editores, 1981.

BRUNO, Lúcia (org.). Educação e trabalho no capitalismo contemporâneo. São Paulo: Atlas, 1996.

CAHIERS DU GEDIIST n 19 - Travail, espaces et profissions. Paris: Harmattan, 1997.

CASTEL, Robert. As metamorfoses da questão social. Uma crônica do salário. São Paulo: Vozes, 1998.

CASTEL, Robert et al. "Chômage: Le cas français. Collection des rapports officiels. Rapport au Premier ministre". Paris: La Documentation Française, 1997.

CHESNAIS, François. A mundialização do capital. São Paulo: Xamã, 1996.

COMITÉ DE LA CONDITION FÉMININE DE LA CONFEDERATION SYNDICALE NATIONALE (CSN). "On vit pas d'amour et d'eau fraîche ou Quelle est la valeur du travail des femmes". $53^{\text {ème }}$ Congrès. Montreal, 1986.

. Des emplois pour tout le monde. Montréal: Saint-Martin, 1983.

COMMAILLE, Jacques. Les stratégies des femmes. Travail, famille et politiques. Paris: La Découverte, 1993.

COSTA, Albertina de Oliveira e BRUSCHINI, Cristina (orgs.). Uma questão de gênero. Rio de Janeiro: Rosa dos Tempos; São Paulo: Fundação Carlos Chagas, 1992.

DEDECCA, Cláudio Salvadori e BRANDÃO, Sandra M.C. "Crise, transformações estruturais e mercado de trabalho". In: Crise Brasileira: Anos oitenta e governo Collor. São Paulo: CUT (DESEP) e Instituto Cajamar (INCA), 1993.

DIEESE - Estudos Setoriais. Terceirização e reestruturação produtiva do setor bancário no Brasil. São Paulo: Dieese, nº 2, julho 1994.

DONIOL-SHAW, Anne Lerolle. "L'évolution du rapport genre-qualification: Question d'identité et de pouvoir". Cahiers du GEDISST - Groupe d'études sur la division sociale et sexuelle du travail. Paris: Institut de Recherche sur les Sociétés Contemporaines - CNRS, 1993. 
DORÉ, Michel e FERLAND, Guy. Prendre les devants dans l'organization du travail. Montréal: CSN, 1992.

DUPUY-HERELLE, Evelyne. Femmes au chômage. Marseille: Hommes et Perspectives; Paris: EPI, 1997.

FREYSSENET, Michel e HIRATA, Helena Sumiko. "Mudanças tecnológicas e participação dos trabalhadores: O CCQ no Japão". RAE - Revista de Administração de Empresas, vol. 25, nº 3, pp. 5-21, 1985.

FUNDAÇÃO INSTITUTO BRASILEIRO DE GEOGRAFIA E ESTATÍSTICA (IBGE). PNAD. 1981 e 1990.

FUNDAÇÃO SISTEMA ESTADUAL DE ANÁLISES DE DADOS (SEADE). "Mulher e Trabalho - Especial". 1997.

GITAHY, Leda (org.). Reestructuración productiva, trabajo y educación en América Latina. Campinas: IG/Unicamp, Buenos Aires: RED CIIDCenep, 1994.

GORZ, André. Capitalisme, socialisme, écologie. Paris: Galilée, 1991.

HARVEY, David. A condição pós-moderna.Uma pesquisa sobre a origem da mudança cultural. São Paulo: Loyola, 1992.

HIRATA, Helena Sumiko (org.). Sobre o "modelo" japonês. Automatização, novas formas de organização e de relações de trabalho. São Paulo: Edusp, 1993.

HIRATA, Helena. "Da polarização das qualificações ao modelo da competência: A evolução do debate no contexto dos novos paradigmas de organização industrial". São Paulo. Simpósio Inovações tecnológicas, novos padrões de organização do trabalho e qualificação da mão-de-obra. Workshop Trabalho e Educação, ANPED. 44 ${ }^{\mathrm{a}}$ Anual da SBPC, 1992. (mimeo.)

"Travail et division sexuelle du travail. Comparaisons internationales du travail industriel". Mémoire de synthése pour l'habilitation à diriger recherches. Université de Versailles SaintQuenti-en-Yvelines, 1997.

HOBSBAWM, Eric. A era dos extremos. São Paulo: Companhia das Letras, 1995.

HYMAN, R. "Plus ça change? The theory of production and the production of the theory". In: POLLERT, A. (org.), Farewell to flexibility. Oxford: Blackwell, 1991. 
IANNI, Octávio. Teorias da globalização. $2^{\text {a }}$ ed. Rio de Janeiro: Civilização Brasileira, 1996.

INSTITUTO DE ANÁLISES SOBRE O DESENVOLVIMENTO ECONÔMICO SOCIAL (IADES). "Perfil da Categoria Bancária em São Paulo". Sindicato dos Empregados em Estabelecimentos Bancários em São Paulo, 1993. (Mimeo.)

JOBERT, Annette; MARRY, Catherine e TANGUY, Lucie. Éducation et travail en Grande Bretagne, Allemagne et Italie. Paris: Armand Colin, 1995.

KARTCHEVSKY, Andrée et al. O sexo do trabalho. Tradução: Sueli T. Cassal. Rio de Janeiro: Paz e Terra, 1986.

KERGOAT, Daniele; IMBERT, Francoise; LE DOARÉ, Helene e SENOTIER, Daniele. Les infirmières et leur coordination: 1988-1989. Paris: Lamarre, 1992.

KERGOAT, Danièle. "Présentation". In: Cahiers du GEDISST - Groupe d'études sur la division sociale et sexuelle du travail. Paris: Institut de Recherche sur les Sociétés Contemporaines - CNRS, 1993.

KOPP, Anatole. Quando o moderno não era um estilo mas sim uma causa. São Paulo: Nobel/Edusp, 1990.

KURZ, Robert. O colapso da modernização. São Paulo: Paz e Terra, 1993.

LEITE, Elenice. "Reestruturação produtiva, trabalho e qualificação no Brasil". In: BRUNO, Lúcia (org.), Educação e trabalho no capitalismo contemporâneo. São Paulo: Atlas, 1996.

LEITE, Márcia de Paula. O futuro do trabalho. Novas tecnologias e subjetividade operária. São Paulo: Scritta, 1995.

LÉVY, Pierre. As tecnologias da inteligência. O futuro do pensamento na era da informática. São Paulo: Ed. 34, 1996.

O que é virtual. São Paulo: Ed. 34, 1996.

MARGINSON, O. The employment structure of larges companies. In: POLLERT, A. (org), Farewell to flexibility. Oxford: Blackwell, 1991.

MARTINS, Heloísa de Souza e RAMALHO, José Ricardo (orgs.). Terceirização. Diversidade e negociação no mundo do trabalho. São Paulo: Hucitec/Cedi/Nets, 1994.

MARUANI, Margareth (coord.). Les Cahiers du Mage. Égalité, équité, discrimination: Hommes et femmes sur le marché du travail. Paris, 
CNRS et Communautés Européennes, Services des Droits de Femmes, $\mathrm{n}^{\circ}$ 2, 1997.

MATTOSO, Jorge Eduardo. "Crise, transformações produtivo-tecnológicas e trabalho. Panorama visto do Brasil". Cadernos do Cesit (texto para discussão $n^{\circ}$ 7). Campinas: Instituto de Economia da Unicamp, 1992. A desordem do trabalho. São Paulo: Scritta, 1995.

MOURA, A. "O sistema financeiro nacional no contexto da reestruturação". Palestra proferida no Cebrap, 1997.

NETO, José Francisco Siqueira. "Políticas sindicais e mudanças na legislação do trabalho no Brasil". Cadernos do Cesit (texto para discussão no 8). Campinas: Instituto de Economia da Unicamp, 1992.

NICOLE DRANCOURT, Chantal. "Organisation du travail des femmes et flexibilité de l'emploi". Sociologie du Travail, XXXII, n 2, 1990.

OFFE, Claus. Capitalismo desorganizado. São Paulo: Brasiliense, 1989. . "Trabalho: A categoria-chave da sociologia?". Revista Brasileira de Ciências Sociais, no 10, vol. 4., São Paulo: Associação nacional de pós-graduação e pesquisa em ciências sociais, junho, 1989.

OLIVEIRA, Carlos Alonso Barbosa de. "Política de ajuste econômico e sindicatos no Brasil". Cadernos do Cesit (texto para discussão no 9). Campinas: Instituto de Economia da Unicamp, 1992.

OLIVEIRA, Carlos Alonso B. de e MATTOSO, Jorge Eduardo L. (orgs.). Crise e trabalho no Brasil. Modernidade ou volta ao passado. São Paulo: Scritta, 1996.

OLIVER, N. e WILKINSON, B. "Japanese manufacturing techniques and personnel and industrial relations practice in Britain: Evidence and implications". Bristish Journal of Industrial Relations, vol. 27, $\mathrm{n}^{0} 1$, 1988.

OMNES, Catherine. Ouvrières Parisiennes. Marchés du travail et trajectoires professionnelles au 20 ème siècle. Paris: Éditions de l'EHESS, 1997.

ONU. Valoriser le travail des femmes. Nova York, 1991.

PEREIRA, Vera Maria Cândido. O coração da fábrica: Estudo de caso entre operários têxteis. Rio de Janeiro: Campus, 1979.

PESSIS-PASTERNAK, Guitta (org.). Do caos à inteligência artificial: Quando os cientistas se interrogam. São Paulo: Edunesp, 1993. 
RIZEK, Cibele Saliba. "Interrogações a um campo teórico em crise". Tempo Social. Revista de Sociologia da USP, № 6, S. Paulo, jan-fev, pp. 147-179.

ROGERAT, Chantal. "Chômage et égalité des chances. La division sexuelle du travail revisitée". Les Cahiers du MAGE. Marché du Travail et Genre, nํㅜ 3, abril de 1995.

ROLLE, Pierre. "O que é qualificação do trabalho". São Paulo, 1987. (Mimeo.)

ROMANELLI, Geraldo. "O provisório definitivo: Trabalho e aspirações de bancários em São Paulo". Dissertação de mestrado em ciências sociais. São Paulo, Faculdade de Filosofia, Letras e Ciências Humanas da USP, 1978, 2 vols.

ROPÉ, Françoise e TANGUY, Lucie (orgs.). Saberes e competências. O uso de tais noções na escola e na empresa. Campinas: Papirus, 1997.

SABÓIA, João. "O Terciário: Um setor em crescimento no Brasil". Setor Terciário. São Paulo em Perspectiva. Fundação Sistema Estadual de Análise de Dados (Seade), 6 (3), São Paulo, jul./set. 1992.

SCOTT, Joan. "Women's history and rewriting of history". In: FARNHAM, Cristi. The impact of feminist research in Academy. Bloogmington: Indiana University Press/Polis, 1987.

SEADE-DIEESE. Boletim PED (Pesquisa de Emprego e Desemprego) Estudo Especial, "Os bancários da grande São Paulo: Trajetória recente da ocupação". São Paulo, 1994, № 114.

SEAGER, Joni. Atlas. Des femmes dans le monde.Émancipation ou opression: Un paysage contrasté. Paris: Autrement, 1997. (Collection Atlas/Monde)

SEGNINI, Liliana. "Novas formas de relações empregatícias e qualificações requeridas em um contexto altamente informatizado: Análise do sistema financeiro no Brasil”. Projeto de pesquisa. Convênio Cedes/ Unicamp financiado pela Finep, CNPq, FAE/Unicamp, 1995.

"Novas formas de relações empregatícias e qualificações requeridas em um contexto altamente informatizado: Análise do sistema financeiro no Brasil". Relatórios I; II; III. Convênio Cedes/ Unicamp financiado pela Finep, CNPq, FAE/Unicamp, janeiro 1996; agosto 1996; janeiro 1997.

. Mulheres no trabalho bancário: Difusão tecnológica, qualificação e relações de gênero. São Paulo: Edusp, 1998. 
SINGER, Paul. "Desemprego e exclusão social". São Paulo em Perspectiva, vol. 10, nº 1, jan.-mar. 1996.

SOUZA-LOBO, Elizabeth. A classe operária tem dois sexos: Trabalho, dominação e resistência. São Paulo: Brasiliense, 1991.

TANGUY, Lucie. Éducation et travail en Grande Bretagne, Allemagne et Italie. Paris: Armand Colin, 1975.

. "La formation, une activité sociale en voie de définition?". In: De COSTER, M. e PICHAUT, F., Traité de sociologie du travail. Bruxelas: De Boeck, Université, 1994.

. "Construction de la categorie formation dans un contexte de chômage en Grande-Bretagne". Revue Sociologie du Travail. Paris: Dunod, $\mathrm{n}^{\circ}$ 4, 1995.

TANGUY, Lucie e ROPÉ, Françoise (orgs.). Savoirs et compétences: De l'usage de ces notions dans l'école et l'entreprise. Paris: L'Harmattan, 1994.

THÉBAUD-MONY, Annie. "Sous-traitance, rapport sociaux, citoyenneté et santé". In: Dossier Sous-Traitances. Travail $n^{\circ} 28$. Paris, Alternatives Economiques, 1993.

VELTZ, Pierre e ZARIFIAN, Philippe. "Vers de nouveaux modèles d'organisation". Sociologie du Travail. Dossier-Débat. Systèmes productifs: Les modèles en question. Montrouge: Dunod, XXXV, (1), pp. 3-25, 1993.

VIRILIO, Paul. A Arte do motor. São Paulo: Estação Liberdade, 1996.

ZARIFIAN, Philippe. "Les nouvelles aproches de la produtivité". Brasília. Seminário Ipea/Iplan, 1989. (Mimeo.)

- "Qualification collective et automatisation: Le cas de la siderurgie". Formation-Emploi, no 1, 1983, pp. 37-51. 